\title{
Grupos ativistas e as funções de Relações Públicas: os casos dos lesados do BPN e do BES
}

\author{
Sónia Pedro Sebastião \& Daniela Vila Verde \\ ISCSP, CAPP-FCT, ULisboa / ISCSP, ULisboa \\ E-mail: ssebastiao@iscsp.ulisboa.pt / danielac1992@gmail.com
}

\begin{abstract}
Resumo
Partindo de um modelo teórico de análise ancorado na teoria pós-moderna de relações públicas (e.g. Holtzhausen, 2000), na teoria situacional da resolução de problemas (Kim \& Grunig, 2011) e recorrendo ao método qualitativo, procura-se neste estudo: identificar e caracterizar os clientes lesados das instituições bancárias em estudo classificados como "públicos ativos" (Hallahan, 2000); compreender o que motiva a cobertura mediática das ações desenvolvidas pelos grupos de ativistas do BPN e do

ções públicas (desempenhadas pelos representantes dos grupos de lesados) na defesa, negociação e promoção dos interesses destes grupos. Conclui-se sobre a importância das funções de relações públicas para a ação comunicativa que assegure a captação da atenção dos media (organização e mobilização de manifestações, notas informativas, conhecimento e instrumentação dos critérios de noticiabilidade) sem que a sua utilização seja efetivamente desenvolvida por profissionais da área.
\end{abstract} BES; e evidenciar a importância das funções de rela-

Palavras-chave: teoria pós-moderna das relações públicas; ativismo; crise financeira; estudo qualitativo.

\section{INTRODUÇÃO}

$\mathrm{O}$ sistema bancário entrou em colapso nos Estados Unidos da América, em 2008, com a falência do banco Lehman Brothers (Banco de Portugal, 2012). No entanto, como vivemos num mundo globalizado, a crise rapidamente se alastrou a outros países, inclusive a Portugal. A crise provocou o pedido de ajuda externa ao Fundo Monetário Internacional (FMI), em 2011, e implicou o resgate financeiro do país.

Portugal foi notado por algumas agências de classificação de risco de crédito, tais como a Moody's, Standard \& Poors e a Fitch como "lixo", deixando o sistema bancário português numa situação delicada (Trading Economics, 2016). Nestas circunstâncias, algumas instituições bancárias tiveram a necessidade de pedir financiamento a outras entidades (Visão, 2014). O abundar

Data de submissão: 2017-12-20. Data de aprovação: 2018-06-28.

A Revista Estudos em Comunicação é financiada por Fundos FEDER através do Programa Operacional Factores de Competitividade - COMPETE e por Fundos Nacionais através da FCT - Fundação para a Ciência e a Tecnologia no âmbito do projeto Comunicação, Filosofia e Humanidades (LabCom.IFP) UID/CCI/00661/2013.
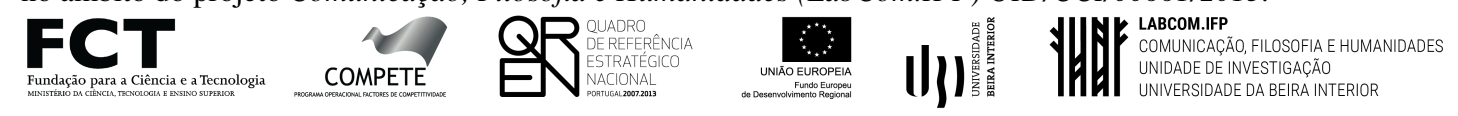
destes pedidos levou a auditorias externas às contas das entidades bancárias revelando casos de corrupção. Estes afetaram a reputação das instituições financeiras, conduzindo à sua descredibilização e à diminuição da confiança no sistema bancário (Vale \& Moreira, 2016), e à dissolução das duas instituições em estudo: o Banco Português de Negócios (BPN) e o Banco Espírito Santo (BES).

A crise nestas instituições bancárias alastrou-se aos seus clientes e integrou a agenda mediática. Os órgãos de comunicação social publicaram várias peças sobre o BPN e o BES, assim como, sobre os seus lesados, antigos clientes que ficaram sem o dinheiro investido em papel comercial.

Nesta investigação, os objetivos são: perceber como se organizam os públicos ativistas (clientes lesados); evidenciar a relação estabelecida entre os órgãos de comunicação social, os representantes das instituições bancárias e dos grupos de clientes lesados, destacando as funções de relações públicas nas reivindicações dos grupos ativistas que incluem os clientes lesados do BPN e do BES.

Por conseguinte, o artigo organiza-se em três pontos. No primeiro, evidenciam-se os contributos teóricos da teoria pós-moderna de relações públicas (e.g. Holtzhausen, 2000) e a teoria situacional da resolução de problemas (Kim \& Grunig, 2011), relacionada com a teoria situacional dos públicos (Grunig \& Hunt, 1984) e com a caracterização dos públicos ativos (Hallahan, 2000). No segundo explanam-se as opções metodológicas e o design de pesquisa, concretizado no ponto 3. Neste apresentam-se e discutem-se os resultados obtidos com a recolha de informação nas entrevistas semi-estruturadas a informadores qualificados e no clipping.

\section{Relações Públicas e Ativismo Social}

$\mathrm{Na}$ última década temos assistido a um aumento dos movimentos ativistas. Estes grupos organizam-se e planeiam estratégias para pressionar os grupos dominantes com vista à resolução de problemas. Neste enquadramento teórico visa-se compreender o ativismo, identificar os públicos ativistas, bem como evidenciar as ações que estes desenvolvem para serem ouvidos nas esferas públicas.

\section{Da teoria da excelência à teoria pós-moderna}

As relações públicas são um campo do saber com a sua própria base de pesquisa e teoria, que tem vindo a sofrer um desenvolvimento substancial em termos de investigação académica. Contudo, a procura por uma única definição do conceito e o isolamento científico da disciplina até aos anos 90, levou a uma fraca visão do papel das relações públicas nas organizações (Gonçalves, 2010).

Para Grunig e Hunt (1984), as funções de relações públicas promovem o diálogo entre a organização e os seus públicos e contribuem para a harmonia social evitando conflitos, pela satisfação de interesses mútuos (Grunig \& Hunt, 1984). Segundo o modelo simétrico bidirecional proposto pelos autores, os PRP estabelecem relações de longo prazo com os públicos, na tentativa de conciliar expetativas e objetivos com o intuito de criar valor para a organização. É neste contexto que Grunig e Hunt (1984) se focam para construir a teoria sistémica da excelência. Segundo esta 
abordagem, uma organização enquanto sistema aberto, é uma estrutura em constante mudança que interage com o meio envolvente e tem capacidade de reajustamento. Neste processo, os PRP estabelecem a comunicação com o ambiente que rodeia a organização, contribuindo para o equilíbrio e sobrevivência desta (Gonçalves, 2010; Tench \& Yeomans, 2009).

A teoria da excelência tem sido alvo de críticas no seio da pesquisa e da prática de relações públicas. De acordo com L'Etang (2005), a teoria crítica desafiou os pressupostos do paradigma dominante das relações públicas, ao considerar que a comunicação bidirecional - que promove o diálogo e a compreensão mútua - é um modelo idealista com interesses camuflados, uma vez que, são as organizações que detêm o controlo do poder e impõem o seu interesse aos públicos (L'Etang, 2005; Tench \& Yeomans, 2009).

O capitalismo, sistema dominante do mundo ocidental e característico da modernidade, é um sistema desigual, onde quem detém mais capital, é quem detém mais poder. O poder encontrase concentrado em grandes grupos económicos, que podem subjugar a voz das minorias. As organizações podem, por conseguinte, exercer maior controlo do poder e maior influência social que os seus públicos.

Com o contributo de vários sociólogos, entre os quais Bauman (2001), a sociedade contemporânea (também apelidada de pós-moderna) é vista como mais dinâmica e volátil, onde as relações humanas são menos permanentes e deixam de ser guiadas pelos padrões éticos existentes na modernidade. Esta fase é essencialmente marcada pela incerteza e pela individualização (Bauman, 2001) influenciando a enunciação da teoria pós-moderna das relações públicas. Esta teoria visa quebrar a dominação ideológica das empresas em relação aos seus públicos e assume-se como crítica à teoria simétrica bidirecional de Grunig e outros (1992). De acordo com a teoria pósmoderna, o consenso não pode ser alcançado, devido à dominação ideológica exercida por quem detém mais poder. Assim, Holtzhausen (2000) sugere que os PRP, ao invés de tentarem alcançar o consenso, devem identificar os tensores internos e externos à organização e promover a cocriação de significados, isto é, a criação de novos significados através das diferenças de opinião existentes no seio dos públicos e que poderão colidir com os interesses da organização. Só desta forma pode existir participação dos públicos na negociação e tomada de decisões.

$\mathrm{O}$ ativismo, processo pelo qual um conjunto de indivíduos pressiona as organizações com o objetivo de alterar políticas, práticas ou outra condição considerada problemática, assume-se como marca da época pós-moderna (Heath, 2013). De acordo com a prática tradicional de relações públicas caracterizada pela teoria da excelência, os ativistas são vistos como públicos externos às organizações e podem ser um entrave ao sucesso organizacional, deste modo o papel do PRP incluía gerir a comunicação com estes públicos para que não surgissem problemas nas organizações.

Contudo, a visão pós-moderna de ativismo vem desafiar a visão normativa da disciplina (Coombs \& Holladay, 2012; Ciszek, 2015; Benecke \& Oksiutycz, 2015). O pós-modernismo vem demonstrar a importância de incluir as diferentes características socioculturais na compreensão da realidade social apelando assim a uma sociedade eticamente responsável. O pós-modernismo surge como reação ao modernismo onde só existe uma verdade alcançável, a dos grupos dominantes (Holtzhausen, 2000). Os pós-modernos reconhecem que o ambiente social está cada vez mais fragmentado, com um maior número de públicos ativos, que por sua vez, se tornaram especialistas em fazer ouvir a sua voz utilizando instrumentos de comunicação "tradicionais" (pela participação 
no agenda-building) e as "novas" tecnologias da informação e comunicação (em especial as redes sociais online) (Hallahan, 2000; Holtzhausen, 2000; Tench \& Yeomans, 2009).

Esta abordagem teórica vem propor uma prática diferente de relações públicas. Em contexto organizacional, os PRP devem tornar-se os ativistas da organização, de forma a conseguirem atenuar as estruturas dominantes de poder, contribuindo para o atender das diferentes vozes e para uma consequente democracia deliberativa (Holtzhausen, 2000). De acordo com a teoria crítica, os PRP utilizam a comunicação para criar poder e é através deste poder que as organizações conseguem dominar os públicos. Os públicos ativos, com a ajuda de um PRP ativista (conceção pós-moderna), podem utilizar o poder para transformar a sua relação com a organização e, pela ação comunicativa, prosseguir a resolução dos seus problemas (Kim \& Grunig, 2011).

\section{Os públicos, a ação comunicativa e a resolução de problemas}

O conceito de "públicos" é omnipresente nas definições de relações públicas. Os públicos são grupos de indivíduos com características e interesses em comum que influenciam a atividade organizacional direta ou indiretamente (Sebastião, 2009, p. 91). Dada a sua capacidade de influenciar a atividade organizacional é importante que sejam identificados e caracterizados para antecipar ou contrariar as consequências dos seus comportamentos, e adequar as mensagens comunicativas. É neste contexto que Grunig e Hunt (1984) propõem a teoria situacional dos públicos. Para identificar os públicos e medir a perceção destes face a questões ou problemas, os autores utilizam três variáveis independentes: reconhecimento do problema, nível de constrangimento e nível de envolvimento; e duas variáveis dependentes: procura e processamento de informação. A variável reconhecimento do problema designa o momento em que os indivíduos percebem que as ações de uma organização podem ter implicações na sua vida. Se estas ações tiverem implicações, os indivíduos tornar-se-ão mais ativos tanto na procura de informação, como na tentativa de resolução do problema. O nível de constrangimento ocorre quando os indivíduos se sentem reprimidos a agir, se esta limitação for elevada, os públicos não têm interesse em procurar informação e envolver-se com a organização. Por último, o nível de envolvimento diz respeito à relação que os públicos têm com a organização. Quanto maior for a sua envolvência, menor será a sua propensão para procurar informações e maior será a informação processada que lhes será transmitida.

Os públicos tornam-se ativos quando estão envolvidos com a organização, enfrentam consequências dos atos organizacionais, reconhecem-nas, e quando se sentem afetados, organizam-se para planear o seu comportamento que pode ter influência negativa na organização. Os públicos ativos apresentam um elevado nível de envolvimento e de reconhecimento do problema. De acordo com Dozier e outros (2016), os públicos ativos além de utilizarem uma comunicação ativa para a resolução de problemas, são indivíduos digitalmente ativos que utilizam as novas tecnologias como uma ferramenta para as mudanças. Os públicos passivos não demonstram interesse pela organização não afetando o seu funcionamento.

A teoria situacional dos públicos proporciona informação a uma organização acerca dos seus

públicos. É uma teoria situacional e, por conseguinte, cada organização tem a sua tipologia de públicos, que varia conforme o seu reconhecimento de problemas. Deste modo, é importante a 
existência de um PRP que identifique os públicos, e que seja capaz de gerir a comunicação da organização, de forma a evitar ou controlar situações danosas para a mesma (Gonçalves, 2010).

Ainda em termos de caracterização dos públicos, Kim e Grunig (2011) apresentam a teoria da resolução de problemas (TRP), que prevê o papel da ação comunicativa dos públicos na resolução de problemas. Este modelo da ação comunicativa amplia as variáveis dependentes da teoria situacional dos públicos. A TRP pretende compreender como é que os públicos se organizam e comportam em termos comunicativos na resolução de problemas. Esta teoria é constituída por três pares de variáveis organizadas de acordo com o comportamento passivo ou ativo de procura e partilha de informação por parte do indivíduo. Para otimizar a solução dos problemas é necessário selecionar a informação, este domínio, integra duas variáveis: a procura de informação, feita de acordo com a relevância do assunto para o indivíduo. A procura ativa de informação sobre um assunto específico pode dotar o indivíduo de informação suficiente para a resolução de problemas; e a informação permitida, que se traduz num comportamento passivo, onde não existe procura de informação.

O domínio da transmissão de informação também integra duas variáveis: o encaminhamento da informação e a partilha de informação. O indivíduo que partilha informação apenas quando solicitado, tem um comportamento passivo; o indivíduo que encaminha a informação de forma proactiva na esperança de encontrar uma solução para o seu problema, adota um comportamento ativo. Neste caso, o objetivo é descobrir alguém que partilhe o mesmo problema para encontrar uma solução conjunta. Por conseguinte, os públicos tornam-se ativistas quando existe a aplicação de uma solução coletiva proveniente de uma transmissão ativa de informação (Kim \& Grunig, 2011).

De acordo com a TRP, o reconhecimento do problema é definido pela falta de uma solução imediata para o contratempo. Existe um conjunto de fatores que influenciam a forma como as pessoas percecionam o problema: o reconhecimento do envolvimento, o reconhecimento de restrições e o reconhecimento do problema. A ação comunicativa é afetada por estes três fatores. Se o nível de envolvimento e o reconhecimento do problema forem elevados, o indivíduo terá um comportamento ativo na comunicação. No entanto, se o seu reconhecimento de restrição for elevado o seu comportamento será passivo.

Em suma, nem todos os públicos são iguais, nem afetam da mesma forma as organizações, sendo importante conhecê-los. As teorias acima descritas permitem caracterizar os públicos ativos que reconhecem problemas e aferir o seu envolvimento na resolução desses mesmos problemas através de ações comunicativas.

\section{As relações com os jornalistas e a noticiabilidade}

A assessoria mediática é a função das relações públicas diretamente associada aos órgãos de comunicação social, pois é caracterizada por assegurar as relações entre a organização e o público estratégico dos jornalistas. Estas relações de entendimento permitem aos PRP criar imagens positivas das organizações através dos media, uma vez que os órgãos de comunicação social chegam ao público em geral de forma massificada. 
De acordo com Schönhagen e Meißner (2016) existem dois fatores que motivaram a relação dos PRP com os media: a parcialidade dos jornalistas, que por vezes denegriam a imagem de pessoas ou organizações e a crescente diferenciação social. Para contrariar a parcialidade jornalística, surgiram no século XX os profissionais de relações públicas que tinham como objetivo quebrar o panorama mediático tendencioso. A crescente diferenciação social, consequência da evolução da sociedade e da economia, levou a que os PRP se relacionassem com os jornalistas para conseguirem chegar aos públicos-alvo. Contudo, a hostilidade que existe entre jornalistas e PRP - e que acaba por denegrir a imagem dos últimos - passa pela ânsia da publicity, pela origem e contexto desta. O facto de os PRP tentarem garantir a participação de interesses individuais nos media, não é bem visto pelos jornalistas, uma vez que acusam os PRP de utilizarem técnicas persuasivas com vista ao favorecimento das organizações para as quais trabalham, acabando por considerar a profissão de relações públicas uma transgressão à democracia (DeLorme \& Fedler, 2003). No entanto, Schönhagen e Meißner (2016) referem que o papel dos PRP é um papel legítimo uma vez que inserem no discurso público a comunicação de diferentes atores sociais, contribuindo para uma democracia mais participativa.

Tal como já referimos, a comunicação dos assessores mediáticos é feita para os órgãos de comunicação social. Estes profissionais comunicam por intermédio de conferências de imprensa, press releases, entrevistas, comunicados, newsrooms digitais, entre outros. Esta informação pode ser aproveitada pelos jornalistas nas notícias. Os jornalistas utilizam a informação dos PRP para construírem a agenda mediática, este processo é designado por agenda-building (Araújo \& Lopes, 2013). Os assessores mediáticos são assim fontes de informação dos jornalistas e utilizam técnicas específicas sintonizadas com os critérios jornalísticos, para introduzir no espaço mediático assuntos do interesse das organizações que representam. Isto leva a que as organizações consigam promover-se dentro do espaço público mediático, conseguindo influenciar a opinião pública (Ribeiro, 2014).

Uma boa relação dos PRP com os jornalistas permite às organizações atingir objetivos, tais como: a melhoria da sua imagem pública, um maior e melhor perfil mediático, a mudança das atitudes dos públicos-alvo, a melhoria das relações com a comunidade, e também das relações laborais. É com base neste objetivo que os PRP constroem as suas mensagens que visam a promoção da organização (Tench \& Yeomans, 2009; Theaker, 2004).

Ao elaborarem os conteúdos a fornecer aos jornalistas, OS PRP procuram cumprir critérios de noticiabilidade, abordados pela teoria do newsmaking. De acordo com Galtung e Ruge (1965), os critérios de noticiabilidade são: a frequência, ou tempo necessário para que um evento se desenrole e adquira significado; a amplitude, que se reflete na extensão do acontecimento, isto é, quanto maior for o impacto do acontecimento mais cobertura noticiosa terá; a clareza da mensagem (quanto mais clara for a mensagem melhor os indivíduos irão percebê-la); a significância, que pode ser interpretada de duas formas: o enquadramento cultural do recetor da notícia (uma notícia acerca da música árabe irá chamar à atenção daqueles que se identificam com esta cultura); e a relevância (um acontecimento pode ser distante culturalmente, no entanto pode estar carregado de significado para quem recebe a notícia); a consonância, esta dá-se quando uma mensagem vai ao encontro das expetativas dos indivíduos; o inesperado (quanto maior for, mais atenção terá do público); e, por último, o equilíbrio (sem causar saturação). De acordo com Galtung e Ruge (1965), 
os acontecimentos que respeitem estes critérios de noticiabilidade, terão maior probabilidade de integrar a agenda mediática (agenda-setting).

Deste modo, tal como pudemos observar os media exercem influência sobre a opinião pública (McCombs, 2005; McCombs \& Shaw, 1972; McQuail, 2003). De acordo com Fortunato (2000), os media têm poder em duas dimensões: têm o poder de influenciar o público (tal como reflete a teoria anteriormente explicada); e têm a capacidade de selecionar e enquadrar os acontecimentos que vão expor, indicando às suas audiências o que pensar acerca deles. No entanto, o enquadramento realizado pode ser construído com base na influência dos PRP, estes profissionais concebem estratégias com o intuito de moldar o conteúdo dos media e, consequentemente, a opinião pública. Portanto, tal como refere Ribeiro (2014) existe uma relação triangular entre os PRP, os media e os públicos.

\section{OPÇÕES METODOLÓGICAS}

No desenvolvimento deste estudo adota-se um método qualitativo para a concretização dos seguintes objetivos:

a. Identificar e caracterizar o conjunto de clientes lesados do BPN e do BES;

b. Compreender o que motiva a cobertura mediática das ações desenvolvidas pelos grupos de ativistas do BPN e do BES;

c. Compreender qual a importância que o PRP (ou porta-voz) assume como promotor da comunicação e ações dos lesados do BPN e do BES.

A recolha de dados suportou-se nas seguintes técnicas:

a) Clipping (recolha, sistematização, quantificação e análise de notícias): a técnica do clipping é realizada nas plataformas digitais dos jornais: Público, Jornal de Notícias e Correio da Manhã uma vez que foram as plataformas mais visitadas no mês de fevereiro de 2016 como demonstra o estudo da Marktest (2016). A seleção das notícias tem por base os termos "BPN", "BES", e as suas combinações com os termos "lesados", "protestos", "manifestações".

O período de análise é variável uma vez que as instituições em estudo sofreram crises em diferentes períodos do tempo. Assim, no caso do BPN, o período de recolha dos dados decorre entre novembro de 2008 e novembro de 2009; no caso do BES a recolha de dados decorre entre julho de 2014 e setembro de 2015. De acordo com Mendes e Pereira (2006), o estatuto de crise é atingido quando as organizações não conseguem controlar as consequências das suas ações, o caso começa a ser objeto de cobertura mediática e os públicos passam a ter conhecimento do estado da organização pelos media. Assim a escolha do período de análise inicial justifica-se pela entrada do problema na agenda mediática, que de acordo com as fases da crise apresentadas por Coombs (30 de outubro de 2007), corresponde à fase da crise em si. O período de análise terá a duração de cerca de um ano no caso do BPN, pois os lesados deste caso só integraram a agenda mediática em setembro de 2009 e pouca atenção lhes foi concedida. No que respeita ao BES o caso integrou a agenda mediática de forma mais intensa em julho de 2014, mas só em agosto de 2014 
os lesados começaram a ser mencionados nas notícias, tendo sofrido uma cobertura mais intensa entre fevereiro de 2015 e setembro de 2015.

As notícias recolhidas são classificadas por data, publicação, título, autor, fonte, género jornalístico, atores e instituições presentes, categorias de enquadramento, valores notícia e tom. $\mathrm{O}$ enquadramento das notícias segue uma abordagem dedutiva, pois pretende-se verificar a frequência de presença de certas categorias nas notícias, e tem por base as categorias apresentadas por Semetko e Valkenburg (2000): conflito, interesse humano, consequência económica, moralidade e responsabilidade. O quadro conflito remete para a desavença entre indivíduos ou grupos; o interesse humano motiva o tom dramático da notícia; a consequência económica foca o resultado económico que certo ato pode ter para um indivíduo; a moralidade surge quando a questão é apresentada do ponto de vista moral; e por fim, a responsabilidade ocorre quando a culpa de um acontecimento é atribuída a um indivíduo ou a um grupo. As notícias são também analisadas de acordo com os critérios de noticiabilidade de Galtung e Ruge (1965), com o objetivo de se compreender quais os critérios utilizados na seleção dos acontecimentos para permear a agenda mediática.

Os dados do clipping são sujeitos a análise de conteúdo parcial cumprindo as fases de préanálise, que compreende a exploração e tratamento do material; a codificação e categorização. A definição das categorias segue os critérios de exclusão mútua, homogeneidade, pertinência, objetividade, fidelidade e produtividade (Bardin, 1977). Não se procedeu à fase das inferências atendendo a que, apesar da categorização e da quantificação da frequência de ocorrências, não se procedeu à análise estatística da informação.

b) Entrevista semiestruturada em profundidade a informadores qualificados (assessores mediáticos, jornalistas e lesados): realizaram-se seis entrevistas procurando informação de qualidade estudada em profundidade aos seguintes informadores qualificados (ver tabela 1). As entrevistas foram transcritas integralmente e para cumprir o protocolo ético de entrevista, foram colocadas à disposição de todos os entrevistados. Isabel Vicente, Irina Melo e Diogo Lacerda Machado fizeram pequenas correções ao texto da transcrição, António Henriques concordou com todo o texto transcrito, Ricardo Ângelo e Nuno Vieira não responderam aos emails enviados com a transcrição.

As entrevistas foram sujeitas a análise interpretativa, com o fim de compreender a realidade em torno dos grupos de ativistas recorrendo-se a extratos considerados importantes para exemplificar os resultados da investigação (Santo, 2010). 
Tabela 1. Relação de entrevistados e justificação

\begin{tabular}{|c|c|}
\hline Entrevistado(a) & Justificação \\
\hline Isabel Vicente & Jornalista do Expresso que realizou cobertura ao caso BPN. \\
\hline António Henriques & $\begin{array}{l}\text { Presidente da Associação nacional de defesa dos direitos dos clientes } \\
\text { do BPN (ANDDCBPN). }\end{array}$ \\
\hline Irina Melo & Jornalista da Lusa que realizou cobertura ao caso BES. \\
\hline Ricardo Ângelo & $\begin{array}{l}\text { Presidente da Associação dos indignados e enganados do papel comer- } \\
\text { cial do BES (AIEPC). }\end{array}$ \\
\hline Nuno Vieira & $\begin{array}{l}\text { Advogado de contencioso e estratega jurídico da Associação dos indig- } \\
\text { nados e enganados do papel comercial do BES (AIEPC). }\end{array}$ \\
\hline Diogo Lacerda Machado & Negociador do Governo para o caso BES. \\
\hline
\end{tabular}

Elaboração própria

\section{Desenho de Pesquisa}

Considerando os objetivos desta investigação enunciados anteriormente sistematiza-se na tabela 2 o quadro teórico.

Tabela 2. Contributo do enquadramento teórico nas técnicas do clipping e das entrevistas semiestruturadas

Teoria

\begin{tabular}{|c|c|c|c|}
\hline Técnica & $\begin{array}{c}\text { Teoria Situacional da } \\
\text { Resolução de } \\
\text { Problemas }\end{array}$ & Agenda-building & Newsmaking \\
\hline Clipping & $\begin{array}{c}\text { Identificar os públicos } \\
\text { lesados do BPN e do BES. } \\
\text { Identificar os } \\
\text { problemas expressos } \\
\text { nas reivindicações. }\end{array}$ & $\begin{array}{c}\text { Evidenciar a presença } \\
\text { dos ativistas nas peças } \\
\text { jornalísticas. }\end{array}$ & $\begin{array}{l}\text { Verificar que valores } \\
\text { notícia orientaram a } \\
\text { cobertura jornalística } \\
\text { dos exemplos em } \\
\text { estudo. }\end{array}$ \\
\hline $\begin{array}{c}\text { Entrevistas } \\
\text { semiestruturadas } \\
\text { em } \\
\text { profundidade }\end{array}$ & $\begin{array}{c}\text { Analisar a perceção } \\
\text { dos problemas por } \\
\text { parte dos lesados. } \\
\text { Avaliar a ação } \\
\text { comunicativa dos } \\
\text { lesados. }\end{array}$ & $\begin{array}{l}\text { Verificar o papel dos } \\
\text { lesados enquanto } \\
\text { público ativista e fonte } \\
\text { de informação. }\end{array}$ & $\begin{array}{l}\text { Analisar se os ativistas têm } \\
\text { consciência da importância } \\
\text { dos valores-notícia para } \\
\text { a sua promoção no } \\
\text { espaço mediático. } \\
\text { Compreender a importância } \\
\text { atribuída pelos entrevistados } \\
\text { às funções de relações } \\
\text { públicas. } \\
\text { Verificar os principais crité- } \\
\text { rios de notícia destacados } \\
\text { pelos lesados na sua } \\
\text { ação comunicativa. }\end{array}$ \\
\hline
\end{tabular}

Elaboração própria 


\section{Análise e Discussão dos Resultados}

Neste ponto apresenta-se a análise e discussão dos resultados da pesquisa empírica realizada com base no clipping feito às plataformas digitais dos jornais: Correio da Manhã, Jornal de Notícias e Público, e nas entrevistas semiestruturadas a informadores qualificados (tabela 1). Os resultados são apresentados de acordo com os objetivos de investigação.

\section{Os Movimentos de Lesados do BPN e do BES}

Os lesados são um conjunto de cidadãos que de alguma forma se sentiram prejudicados pelas ações ou pelos objetivos das organizações. Neste contexto, o BPN e o BES deixaram um conjunto de clientes lesados devido à venda não correta de papel comercial. De acordo com os clientes lesados, o papel comercial foi disponibilizado aos clientes como se fosse um depósito a prazo (Carvalho, 2012; Lesados Novo Banco, 2015). Com o fim das duas instituições bancárias, os clientes viram-se sem o dinheiro investido (problema) e reivindicaram (ação comunicativa) com vista a recuperar o dinheiro investido.

Os lesados do BPN fazem-se representar pela ANDDCBPN, associação presidida por António Henriques. Os lesados teriam na altura da crise do BPN uma idade compreendida entre os 55 e os 85 anos, ou seja, são um conjunto da população envelhecido. Os lesados do BES fazem-se representar pela AIEPC, associação presidida por Ricardo Ângelo também ele lesado do papel comercial. De acordo com Ricardo Ângelo, a criação da associação surge com a sua participação nos fóruns do Jornal Económico onde existiam alguns comentários sobre os lesados do papel comercial do BES. Segundo o entrevistado, "criou-se um grupo, inicialmente com cerca de 8 pessoas que não se conheciam (...) passado cerca de 15 dias tínhamos cerca de 70 pessoas". Tendo em conta as proporções do caso e o número de pessoas envolvidas optou-se pela criação de uma associação.

A importância da criação das associações é verbalizada por Diogo Lacerda Machado e Irina Melo, conforme ilustrado na figura 1. 

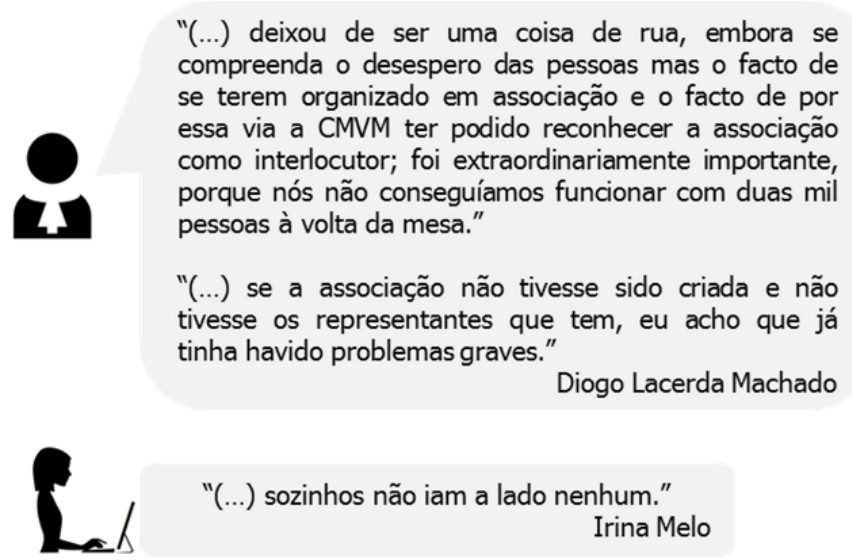

"(...) sozinhos não iam a lado nenhum."

Irina Melo

Figura 1. Declarações sobre a importância das associações de lesados do BPN e do BES

Em termos de representantes, a AIEPC conta com Ricardo Ângelo como presidente e com os advogados Nuno Vieira e Luís Miguel Henrique. A AIEPC tem cerca de 1200 sócios, anónimos, na sua maioria com mais de 65 anos e pertencentes a uma classe social média-baixa. Segundo Ricardo Ângelo "a franja maior dos associados são as pessoas com menos dinheiro, porque as pessoas com mais dinheiro não se expõem com esta facilidade". No que respeita ao valor investido, este acrescenta que "cerca de $95 \%$ das pessoas têm menos de 500 mil euros investidos". Nuno Vieira refere também que os lesados têm uma particularidade em comum: "subscreveram produtos que não eram adequados aos seus perfis de investidor", pois têm baixo conhecimento financeiro e são "investidores não qualificados".

Com o testemunho dos entrevistados é possível sintetizar que os lesados têm pouca literacia financeira, pertencem a uma classe social média-baixa e fazem parte de um grupo envelhecido da população. Apesar do diferente impacto das duas associações de lesados, a caracterização do seu público é bastante semelhante.

De acordo a teoria situacional de resolução de problemas (Kim \& Grunig, 2011), os públicos lesados do BPN e do BES eram inicialmente públicos motivados, com elevado envolvimento com a organização, mas possuíam um baixo conhecimento que os levou a subscreverem produtos pouco adequados aos seus perfis. Contudo, após terem reconhecido a existência de um problema, ou seja, após terem percebido que foram alvo de venda enganosa de papel comercial, tornaram-se num público ativo. Os públicos lesados de ambas as instituições tiveram uma comunicação ativa. Após terem reconhecido a existência de um problema, procuraram informar-se junto de advogados, partilharam a informação por intermédio das associações e concretizaram um conjunto de ações com vista à resolução do problema.

\section{A cobertura noticiosa das ações desenvolvidas pelos lesados do BPN e do BES}

Podemos observar no gráfico 1 que os lesados do BPN pouco integraram a agenda mediática (13 notícias), ao contrário dos lesados do BES (177 notícias). 
Gráfico 1. Número de notícias por órgão de comunicação social

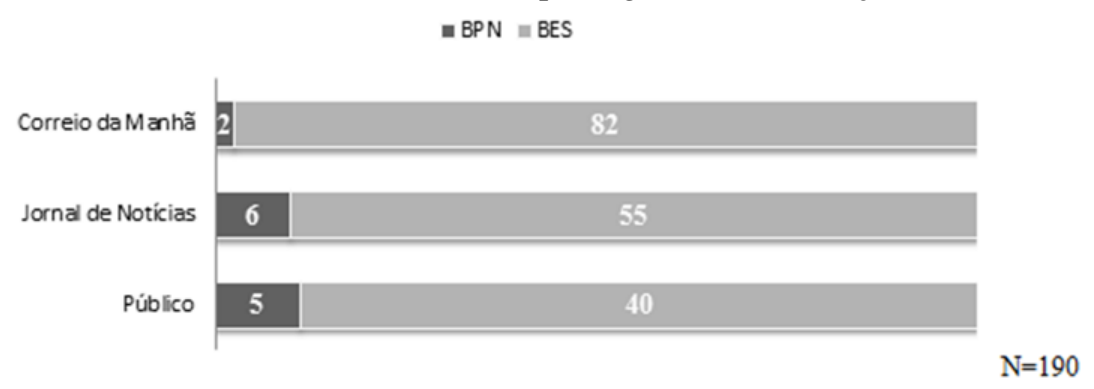

Elaboração própria

A fraca mediatização dos lesados do BPN poderá ter sido motivada pela existência de uma classe política envolvida com pouco interesse na mediatização, pela rápida intervenção do Estado ou pelo mediatismo de outros assuntos relacionados com a falência do banco com perfil mais noticioso (por exemplo, casos de corrupção). Na figura 2 apresentam-se algumas justificações dos entrevistados.

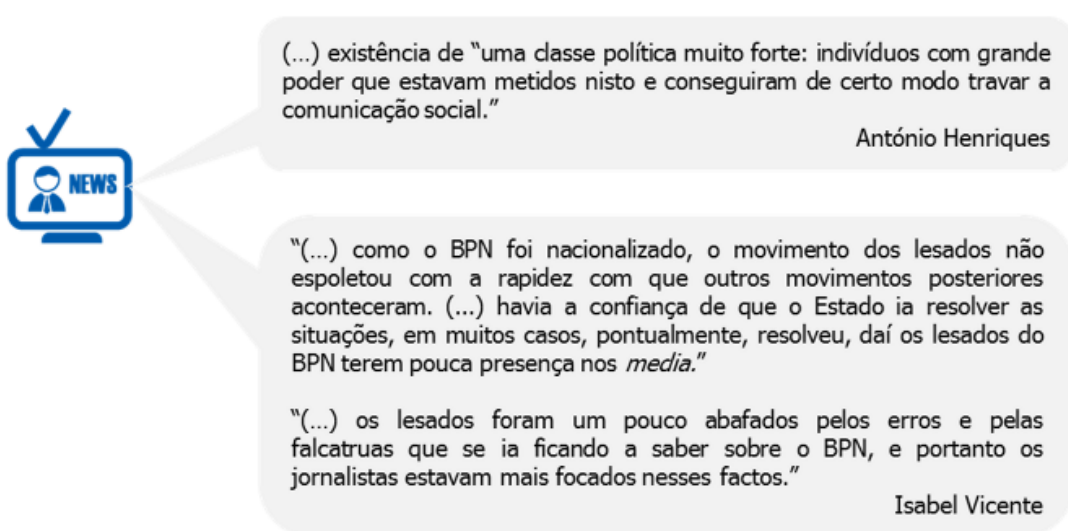

Figura 2. Motivos da fraca cobertura mediática do problema dos lesados do BPN

Contrariamente ao caso BPN, os lesados do BES tiveram uma forte cobertura mediática (177 notícias) - gráfico 1. O mediatismo do caso BES poderá justifica-se pela empatia criada em relação ao problema dos lesados que poderia ter afetado qualquer pessoa. Afinal a instituição BES prestava serviço às massas e era um dos principais anunciantes em Portugal. A figura 3 apresenta algumas das declarações dos entrevistados sobre o mediatismo dos lesados do BES. 


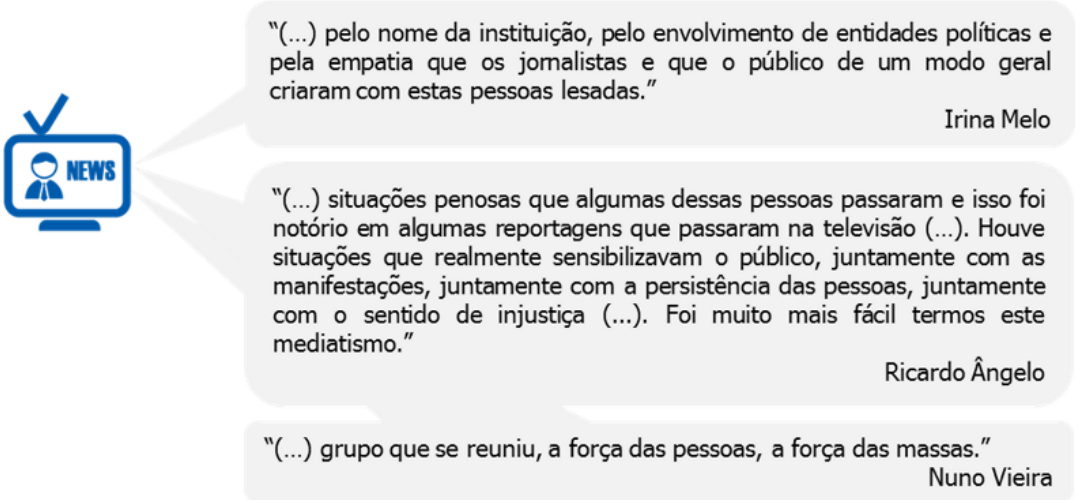

Figura 3. Motivos da elevada cobertura mediática do problema dos lesados do BES

Os critérios de noticiabilidade orientam a seleção dos acontecimentos que devem compor a agenda mediática. No caso BPN, o critério que mais se destaca é o conflito (11), que remete para acontecimentos que induzem a prática de atos como a violência física ou simbólica. Nas notícias analisadas verificaram-se expressões como "confronto" e "conflito", diretamente associadas à violência. O clima de tensão foi gerado essencialmente nas manifestações. Também a relevância (8) e a notabilidade (7) foram valores que orientaram a cobertura mediática (ver tabela 3).

Relativamente ao caso BES, o critério que mais orientou a cobertura mediática também foi o conflito (132). O segundo critério mais encontrado foi a notabilidade (116), uma vez que cerca de 4100 clientes do BES ficaram lesados (Vicente, 2016). Outro dos critérios presentes foi a relevância (56). A noticiabilidade dos acontecimentos relacionados com os lesados do BES justificou-se pela necessidade de explicar às pessoas a crise na instituição, bem como, as suas implicações (ver tabela 3).

Tabela 3. Critérios de noticiabilidade orientadores da cobertura mediática dos casos BPN e BES

\begin{tabular}{clcccc}
\multicolumn{5}{c}{ Número de Menções } \\
& & Correio da Manhã & Jornal de Notícias & Público & Total \\
\hline \multirow{6}{*}{ BPN } & Conflito & 2 & 6 & 3 & 11 \\
& Relevância & 0 & 4 & 4 & 8 \\
& Notabilidade & 2 & 2 & 3 & 7 \\
& Notoriedade & 1 & 0 & 1 & 2 \\
\cline { 2 - 6 } & Total & 5 & 12 & 11 & 28 \\
\hline \multirow{6}{*}{ BES } & Conflito & 61 & 42 & 29 & 132 \\
& Notabilidade & 55 & 39 & 22 & 116 \\
& Relevância & 19 & 22 & 15 & 56 \\
& Notoriedade & 13 & 2 & 9 & 24 \\
& Novidade & 1 & 0 & 0 & 1 \\
\cline { 2 - 7 } & Total & 149 & 105 & 75 & 329 \\
\hline & Elaboração própria & &
\end{tabular}


O tom foi avaliado tendo em conta o texto da notícia, e pode ser positivo, negativo ou neutro. As peças jornalísticas definidas como negativas utilizam expressões como: "confronto", "conflito", "protestos", "invasão", "intervenção policial", "ameaça" e "agressão". As peças classificadas com o tom positivo remetem para os direitos dos lesados e para o cenário de negociação de uma solução para a situação. Por fim, notícias com o tom neutro utilizam uma linguagem denotativa e não refletem nenhuma posição. Deste modo, tal como se pode observar no gráfico 2, em ambos os casos, a maior parte das notícias analisadas tem tom negativo (BPN: 11; BES: 132). Em cada um dos casos, apenas uma notícia pode ser classificada como tendo tom positivo.

Gráfico 2. Tom das notícias segundo os casos BPN e BES

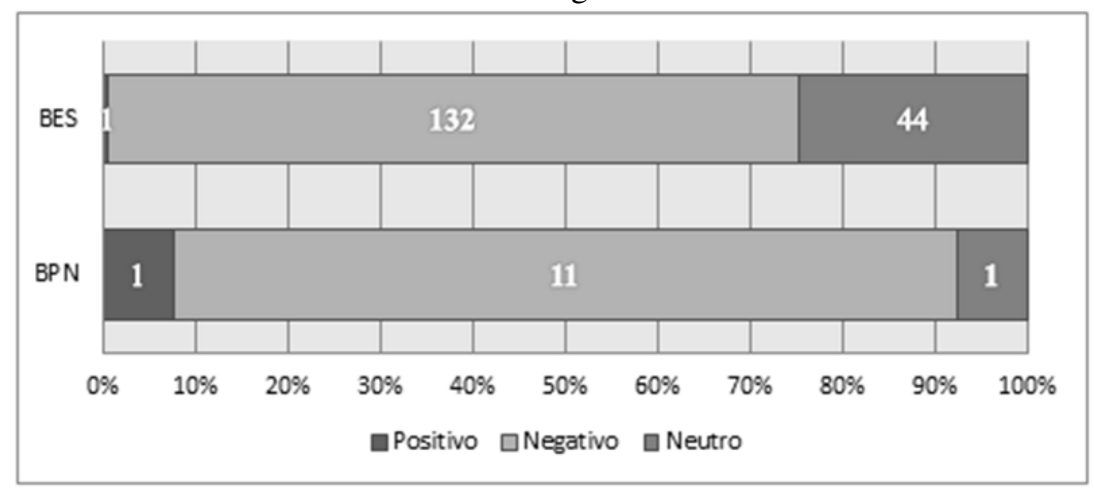

Elaboração própria

O critério jornalístico mais evidente no caso BPN foi o conflito essencialmente gerado nas manifestações. Isabel Vicente revela que o interesse em cobrir os acontecimentos relacionados com os lesados do BPN surgia porque era necessário "explicar o que tinha sido feito mal; para dar voz às pessoas que tinham sido enganadas". Sobre o tom das notícias, a jornalista refere que é importante olhar para o contexto dos acontecimentos para se perceber se são negativos ou positivos. Isabel Vicente considera que a imagem da cobertura sobre os lesados foi positiva. No entanto "em todos os casos há excessos. O contexto em que estavam a protestar era um contexto de quem perdeu tudo, ou quase tudo, portanto bastava um se exaltar para os outros se exaltarem". António Henriques, por sua vez, refere que o poder político poderá ter tido influenciado uma cobertura mediática negativa dos lesados.

Os entrevistados dividem-se em termos de opinião sobre a imagem mediática dos lesados. No caso BES, Ricardo Ângelo refere que era o conflito que tornava os lesados motivo de atenção mediática. Para o presidente da associação, "o que interessava era fazer barulho e bater forte às 12:58h, porque depois o jornalista via que estava a haver barulho e entrava em direto logo com aquela notícia". Já Nuno Vieira refere que o conflito não existiu e que este era criado pelos órgãos de comunicação social. Não obstante, a presença dos lesados em manifestações já era considerada conflituosa pelo seu grau de ativismo. Irina Melo refere que a importância em cobrir os acontecimentos relacionados com os lesados do BES surge porque "são os lesados que demonstram o impacto que tem a queda de um banco com a dimensão do BES". 
Nuno Vieira refere também que havia algumas incorreções nas notícias que podem ter contribuído para uma imagem enganosa dos lesados. Os opinion makers emitiam muitas vezes opiniões desajustadas e falaciosas sobre os lesados do BES. O advogado sublinha "o Jornal Expresso através do Vieira Pereira, que constantemente tinha argumentos contra nós, completamente absurdos (...) houve uma certa confrontação de determinados órgãos, através dos seus opinion makers".

Irina Melo ao contrário dos restantes entrevistados considera que a imagem mediática dos lesados foi essencialmente positiva (ver figura 4). Refere, ainda, que há constrangimentos para noticiar acontecimentos relacionados com o BES: "até quase às vésperas do BES cair, era dos maiores bancos; o BES era uma empresa histórica, com poder económico e político e os jornalistas são pessoas. É difícil afrontar".

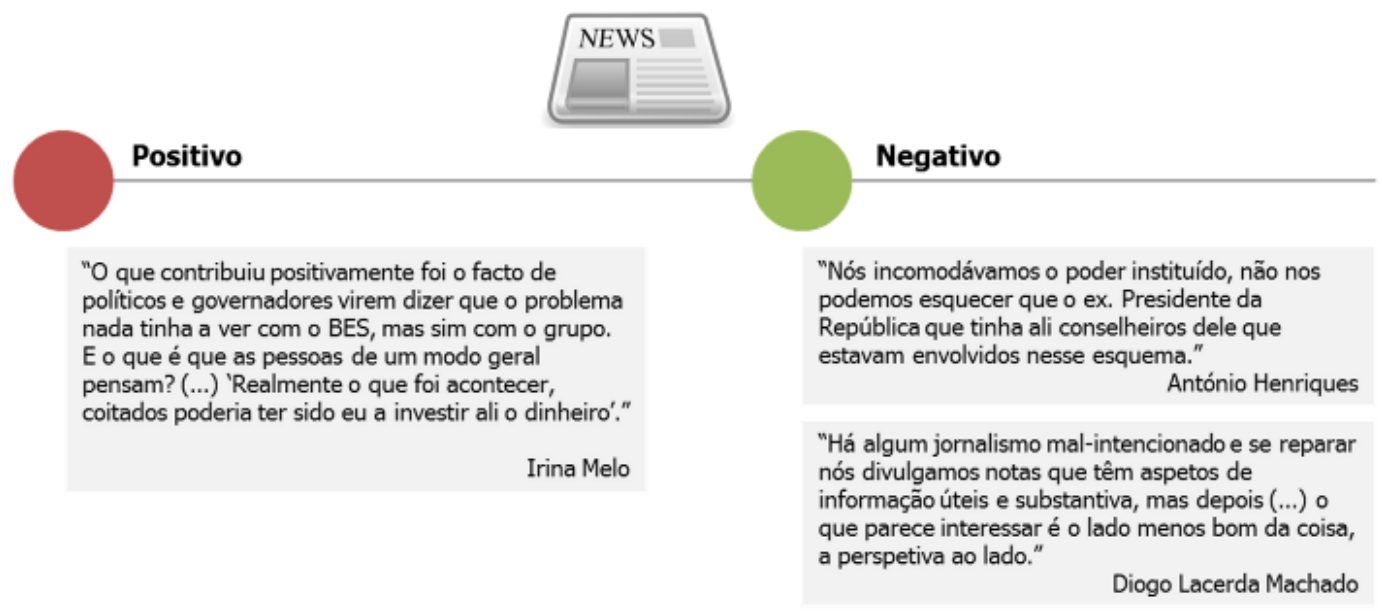

Figura 4. Opinião dos entrevistados sobre a imagem mediática dos lesados

(considerando o tom das notícias)

Tal como evidenciado, os órgãos de comunicação social são veículos utilizados pelos lesados para promover a sua causa junto da opinião pública. A agenda mediática é composta por um conjunto de acontecimentos selecionados de acordo com critérios jornalísticos (Galtung \& Ruge, 1965). Os critérios que orientam a seleção de notícias são conhecidos pelos porta-vozes das associações e permitem-lhes promover-se dentro do espaço mediático, visando chamar a atenção pública e pressionar alguns grupos dominantes (Correia, 2011; McCoombs \& Shaw, 1972; McCoombs, 2005; McQuail, 2003;). O facto de os lesados agirem por esta via oferece-lhes maior força de mobilização. Contudo, a capacidade de mobilização destes grupos, na maior parte das vezes, não é bem vista pelos grupos dominantes. Na opinião de alguns entrevistados, há uma tentativa de abafar as vozes dos lesados no contexto mediático para não afetar a reputação das instituições envolvidas. 


\section{Ações e comunicação dos lesados do BPN e do BES, a importância do PRP (ou porta-voz)}

No que respeita ao papel do PRP ou dos porta-voz como promotores de ações ou da comunicação levadas a cabo pelos lesados, Isabel Vicente refere que no caso BPN a existência de um PRP para tratar a comunicação não foi necessária porque "o assunto vale ou não vale por si, porque há imensa gente profissional de relações públicas a querer comunicar produto por exemplo, e nós não escrevemos e eles são muito profissionais mas nós não escrevemos... Portanto eu acho que não faz diferença". Para António Henriques, o porta-voz não tem poder por sí só, tal como refere "eu sou porta-voz mas por detrás havia uma associação e tínhamos sempre os associados que nos acompanhavam nas manifestações". António Henriques era responsável pela organização das ações levadas a cabo pelos lesados e também pelo estabelecimento da relação com os media. $\mathrm{O}$ mesmo refere que o apoio dos órgãos de comunicação social é uma mais-valia na medida em que dá voz ao grupo de lesados.

O presidente da ANDDCBPN como não tinha qualquer formação em relações públicas contactou agências de comunicação para o ajudarem no tratamento da comunicação. Contudo, estas exigiam custos avultados que não eram suportáveis para a associação.

Para fazer face às dificuldades de mobilização, o representante dos lesados do BPN adotou uma estratégia simples, além de ter criado a associação que conferia aos lesados mais poder e força de mobilização, pensou na realização de várias manifestações. António Henriques numa assembleiageral da ANDDCBPN disse aos lesados "não vamos para as aldeias, vamos para as capitais de distrito e portanto fizemos uma manifestação em Leiria, entendíamos que ali podíamos ter muita gente dada a proximidade. (...) Oito dias depois marquei outra para o mesmo local e fomos lá novamente... Da segunda vez já consegui falar com o Secretário de Estado". Para o presidente da ANDDCBPN a resolução do caso passou por uma questão negocial e pela disponibilidade do Governo em negociar.

Irina Melo também considera que o facto de o porta-voz do movimento não ser um PRP não teve qualquer impacto na cobertura mediática dos lesados do BES, de acordo com a jornalista "era um movimento por si só muito forte, era um movimento que à partida estava vendido, porque representa muitas pessoas". No caso BES estavam também envolvidos um conjunto de indivíduos e instituições importantes, o que desperta a cobertura mediática. Podemos observar no apêndice 1 que instituições como o Banco de Portugal (14), o partido político CDS-PP (11) e personalidades como Pedro Passos Coelho (10) e Paulo Portas (5) surgem nas notícias relacionadas com os lesados do BES. A presença destes líderes políticos tornou o agendamento mediático mais provável face ao critério de noticiabilidade da personalização.

A atividade comunicacional da AIEPC ficou a cargo de Ricardo Ângelo, Nuno Vieira e Luís Miguel Henrique. De acordo com o presidente da associação "foi um processo em que cometemos muitos erros no princípio, porque como é lógico não tínhamos qualquer tipo de experiência mediática nem em comunicação (...). Essa lição foi aprendida à força e mais tarde aprendida também com alguma ajuda". Apesar das dificuldades por vezes sentidas, a AIEPC nunca recorreu a agências de comunicação, segundo Ricardo Ângelo "houve inicialmente várias abordagens de várias agências de comunicação, o problema é que nós não tínhamos fundos para pagar às agências de comunicação". Para Nuno Vieira esta relação com agências nunca se estabeleceu porque, na sua 
opinião, existiam pessoas na associação com capacidades para desempenhar essa função. Além disso, Ricardo Ângelo acrescenta que "não trabalhámos com nenhuma agência de comunicação, até porque somos findáveis. Nós não temos capacidade de alimentar uma agência de comunicação e como é lógico, as agências de comunicação fidelizam-se sempre a quem lhes dá garantia durante anos".

Diogo Lacerda Machado refere também que não havia meios para usufruir do trabalho de um assessor mediático, contudo houve um conjunto de pessoas que exerceram essas funções. O entrevistado salienta ainda que "se pudéssemos ter disposto de meios de alguém muito experimentado, provavelmente poderíamos ter tido uma comunicação mais completa, mais afinada". Contudo, após a formação do grupo de trabalho, a comunicação para os media foi sempre salvaguardada pela nota escrita. De acordo com Diogo Lacerda Machado, o grupo de trabalho acordou a elaboração de notas escritas sempre que fosse útil dar alguma informação de ordem geral, divulgando-a através da agência Lusa "para não dar tratamento discriminatório e desigual".

Para a promoção mediática o grupo de lesados aproveitou o período de campanha eleitoral para as eleições legislativas. Os lesados além de se manifestarem nos comícios, planearam apresentar uma proposta de solução ao caso dos lesados aos dois maiores partidos políticos (Partido Social Democrata, PSD e Partido Socialista, PS). António Costa, líder do PS, aproveitou a proposta na sua campanha política para angariação de votos e, após ter sido eleito, fez-se representar por Diogo Lacerda Machado no processo de negociações com a AIEPC.

Além destas ações, Nuno Vieira refere que "usávamos a ideia de que o Governo se estava a comprometer, sempre que o Governo se comprometia nós tentávamos imediatamente estar mais à frente, nós utilizámos uma estratégia de amplificação para ter mais impacto". Ricardo Ângelo refere ainda que a comunicação foi a sua melhor estratégia, segundo este "tínhamos de ter vozes simples que neste caso tinham que ser vozes que comunicassem e não vozes com grandes complexidades e retóricas e isso fez com que fosse permitido ter o alcance aos media que chegamos a ter e ainda temos".

São vários os estudos que apontam para o PRP como intermediário da comunicação entre a organização e os seus públicos (Gonçalves, 2010; Grunig \& Hunt, 1984). Esta perspetiva é unidirecional porque as organizações tomam as decisões sem envolvimento dos públicos. A teoria pós-moderna de relações públicas vem demonstrar que os públicos ativistas também podem desempenhar funções de relações públicas, pois usam a comunicação com vista ao cumprimento dos seus objetivos (e. g. Ciszek, 2015; Benecke \& Oksiutycz, 2015). Segundo Heath (2013), os ativistas utilizam as estratégias de relações públicas com dois objetivos: influenciar a opinião pública com vista à correção de situações que considerem problemáticas e manter a coesão de forma estruturada e organizada. Para isso utilizam um conjunto de medidas, algumas, conflituosas - boicotes, manifestações, eventos com projeção dramática - e outras informativas que visam a compreensão pela opinião pública dos problemas dos ativistas.

Nos casos em estudo, os ativistas lesados tanto desenvolveram ações conflituosas (por exemplo, as manifestações) e informativas (por exemplo, as notas escritas, entrevistas). Para que estas ações ganhassem a atenção pública, era importante que o grupo de ativistas lesados desenvolvesse relações com os media. A relação que se estabeleceu com os MEDIA foi por vezes forçada pelo grupo de ativistas lesados, pois estes planeavam as suas ações de acordo com os critérios de no- 
ticiabilidade. Os critérios mais utilizados foram o conflito e a personalização. O conflito ocorria no contexto das manifestações e a personalização é usada quando os lesados tentam obter a atenção mediática por intermédio de indivíduos ou instituições importantes (e.g. Banco de Portugal, líderes políticos e partidos políticos) - ver figura 5 .
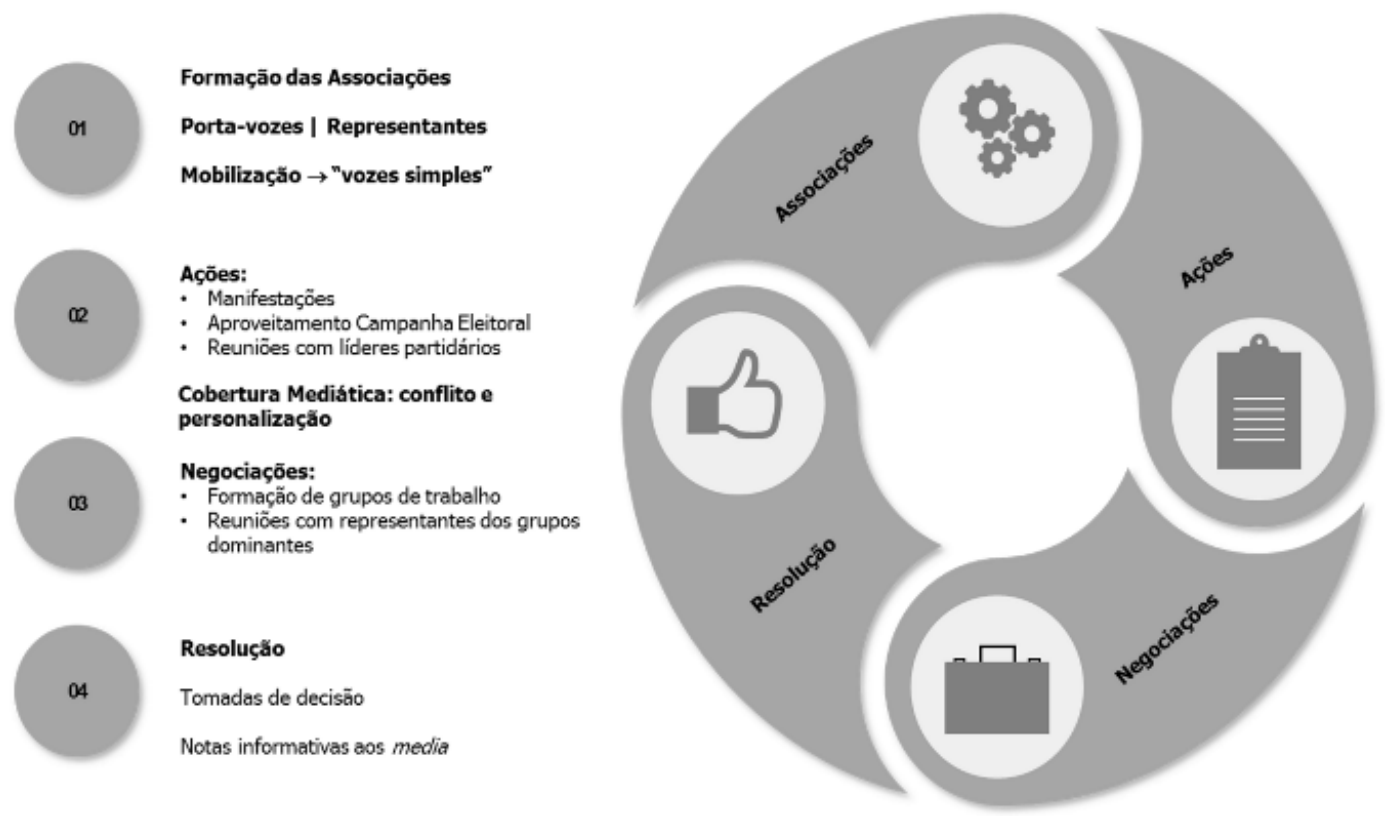

Figura 5. Súmula das ações de comunicação e RP desenvolvidas pelos grupos de lesados

Elaboração própria

\section{CONCLUSÕes}

A presente investigação pretendeu compreender a importância dos media e das funções de relações públicas na projeção das reivindicações dos grupos de ativismo social. Foi possível constatar que os media permitem às minorias entrar no espaço mediático, por norma, confinado a grupos dominantes. São os media que concedem voz e força de mobilização a estas minorias. Também os PRP são importantes pois desenvolvem ações com vista à promoção mediática, tratam da assessoria da comunicação e estabelecem relações com as instituições em crise com o objetivo de apoiar a resolução do problema.

Os públicos lesados do BPN e do BES fazem parte de um conjunto de pessoas envelhecidas, pertencentes a uma classe social media-baixa com pouca escolaridade, que se sentiram enganadas pelo BPN e pelo BES no processo de venda de papel comercial. O grau de envolvimento destes públicos com a organização era elevado, contudo, o grau de conhecimento só aumentou após a formação das associações de lesados. Estas desenvolveram uma comunicação ativa, entre lesados 
e o público em geral, por intermédio dos órgãos de comunicação social, e nas negociações com os representantes das instituições (bancos, Governo e CMVM, 2016).

No que diz respeito à cobertura mediática dos lesados verificou-se, no caso do BPN, que esta não foi tão intensa devido à rápida resolução do caso. No entanto, quando existiu, a cobertura mediática foi (na maior parte das vezes) desencadeada pelo conflito existente nas manifestações. $\mathrm{O}$ caso BES, por sua vez, teve elevada cobertura mediática também motivada pelo conflito associado às manifestações.

O diálogo das instituições bancárias com o grupo de lesados também não existiu. Não houve tentativa de negociação, o que obrigou os lesados a encontrar soluções alternativas, responsabilizando outras instituições para a devolução dos valores investidos. Foi o Governo que se dispôs a negociar com os lesados num espaço próprio e com as entidades competentes. De acordo com o apurado, no caso BES mais detalhadamente, este diálogo não existiu com o objetivo de encontrar o consenso mas sim de promover a cocriação de significados, isto é, a procura de uma nova solução através das perspetivas dos diferentes intervenientes na negociação. O que nos leva a desafiar a teoria dominante (teoria da excelência) de relações públicas.

A partir da nossa análise foi possível perceber que os líderes dos grupos ativistas desempenharam funções de PRP. A criação das associações englobou um número significativo de pessoas; foram concretizadas ações com vista à resolução de um problema (situação de lesados), entre as quais assegurar a comunicação com os media, fazendo todo o trabalho de assessoria mediática, e dialogar com o Governo com vista à resolução da situação. Esta organização em público ativista deu poder ("empoderou") e voz aos lesados tornando-os noticiáveis e relevantes para o processo de negociação.

Este estudo contribuiu para a compreensão do papel dos MEDIA como promotores de uma democracia participativa, apresentando uma visão alternativa à abordagem normativa de relações públicas onde os públicos ativistas são vistos como um problema organizacional. Adotando uma abordagem pós-moderna, as práticas dos grupos ativistas são as mesmas que são utilizadas pelos PRP e os públicos ativistas são mais do que simples públicos externos da organização.

É importante referir que o presente estudo tem por base uma técnica qualitativa que não permite fazer generalizações. Outra das limitações encontradas relaciona-se com a necessidade de rememoração do caso BPN ocorrido em 2008. Pelo crescente número e importância das organizações de sociedade civil, sugere-se para pesquisas futuras, procurar-se compreender, a um nível mais abrangente e sistematizado, a forma de atuação dos grupos ativistas e as respostas dos grupos dominantes aos mesmos.

Apesar destas limitações, este trabalho representa uma contribuição não só para a teoria pósmoderna de relações públicas, ainda pouco estudada em Portugal, como também, para a compreensão da importância da comunicação no equilíbrio do poder de decisão e na promoção de uma democracia mais participativa. 


\section{REFERÊNCIAS BIBLIOGRÁFICAS}

Araújo, R. \& Lopes, F. (2013). Olhando o agenda-building nos textos de saúde: um estudo dos canais e fontes de informação. $8^{\circ}$ SOPCOM Comunicação Global, Cultura e Tecnologia (pp. 749-753). Minho: Centro de Estudos de Comunicação e Sociedade.

Banco de Portugal (2012). Evolução da Solvabilidade do Sistema Bancário - O sistema bancário está hoje mais robusto e mais resiliente. Obtido de Banco de Portugal a 06 de fevereiro de 2017: www.bportugal.pt/sites/default/files/anexos/documentos-relacionados/combp2012020 3.pdf

Bardin, L. (1977). Análise de Conteúdo. Lisboa: Edições 70.

Bauman, Z. (2001). Modernidade Líquida. Rio de Janeiro: Zahar.

Benecke, D., \& Oksiutycz, A. (2015). Changing conversation and dialogue through LeadSA: Anexample of public relations activism in South Africa. Public Relations Review, 41(5): 816-824.

Carvalho, P. T. (2012). O advogado que defende os lesados na "fraude do século". Obtido em Público a 06 de fevereiro de 2017: www.publico.pt/portugal/jornal/o-advogado-que-defendeos-lesados-na-fraude-do-seculo-24310638

Ciszek, E. (2015). Bridging the gap: Mapping the relationship between activism and public relations. Public Relations Review, 41(4): 447-455.

CMVM. (2016). CMVM regista Associação de Defesa dos Clientes Bancários Lesados, Investidores em Papel Comercial, do BES. Obtido em Comissão do Mercado de Valores Mobiliários a 06 de fevereiro de 2017: www.cmvm.pt/pt/Comunicados/Comunicados/Pages/20160404b.as $\mathrm{px}$

Coombs, T. (2007, outubro 30). Crisis Management and Communications. Obtido em Institute for Public Relations a 01 de novembro de 2016: www.instituteforpr.org/crisis-managementand-communications/

Correia, J. (2011). O Admirável Mundo das Notícias: Teorias e Métodos. Covilhã: LabCom Books. Obtido a 10 de abril de 2017: www.labcom-ifp.ubi.pt/ficheiros/20110524-correia_manu al_noticial.pdf

DeLorme, D. \& Fedler, F. (2003). Journalists hostility toward public relations: an historical analysis. Public Relations Review, 29(2), pp. 99-124.

Dozier, D.; Shen, H.; Sweetser, K. \& Barker, V. (2016). Demographics and Internet behaviors as predictors of active publics. Public Relations Review, 42(1): 82-90.

Trading Economics (2016). Portugal - Classificação de Risco de Crédito. Obtido em Trading Economics a 06 de dezembro de 2016: http://pt.tradingeconomics.com/portugal/rating

Fortunato, J. (2000). Public Relations Strategies for Creating Mass Media Content: A Case Study of the National Basketball Association. Public Relations Review, 26(4): 481-497.

Galtung, J. \& Ruge, M. (1965). The Structure of Foreign News. Journal of Peace Research, 2(1): 64-91. 
Gonçalves, G. (2010). Introdução à Teoria das Relações Públicas. Porto: Porto Editora.

Grunig, J., \& Hunt, T. (1984). Managing Public Relations. Wadsworth Publishing.

Grunig, J.; Dozier, D.; Ehling, W.; Grunig, L.; Repper, F. \& White, J. (1992). Excellence in Public Relations and Communication Management. New Jersey: Lawrence Erlbaum Associates.

Hallahan, K. (2000). Inactive Publics: The Forgotten Publics in Public Relations. Public Relations Review, 26(4): 499-515.

Heath, R. (2013). Encyclopedia of Public Relations. London: SAGE Publications.

Holtzhausen, D. R. (2000). Postmodern Values in Public Relations. Journal of Public Relations Research, 12(1): 93-114.

Kim, J.-N. \& Grunig, J. (2011). Problem Solving and Communicative Action: A Situational Theory of Problem Solving. Journal of Communication, 61(1): 120-149.

Lesados Novo Banco (2015). Lesados Novo Banco.Com. Obtido em Lesados Novo Banco a 10 de fevereiro de 2017: http://lesadosnovobanco.com/?page_id=8

L'Etang, J. (2005). Critical public relations: Some reflections. Public Relations Review, 31(4): 521-526.

Marktest. (2016, fevereiro). Ranking NetScope de tráfego web. Obtido em Netscope a 3 de março de 2016: http://net.marktest.pt/netscope/rankings-netscope/ranking-netscope-de-fevereiro-de $-2016 /$

McCombs, M. (2005). A Look at Agenda-Setting: Past, Present and Future. Journalism Studies, 6(4): 543-577.

McCombs, M. \& Shaw, D. (1972). The Agenda-Setting Function of Mass Media. Public Opinion Quarterly, 36(2): 176-187.

McQuail, D. (2003). Teoria da Comunicação de Massas. Lisboa: Fundação Calouste Gulbenkian.

Mendes, A. M. \& Pereira, F. (2006). Crises de ameaças a oportunidades: gestão estratégica de comunicação de crises. Lisboa: Edições Sílabo.

Moloney, K. (2000). Rethinking Public Relations: The spin and the substance. London: Routledge.

Ribeiro, V. (2014). O campo e o triângulo operacional da assessoria de imprensa. In G. Gonçalves \& M. Guimarães, Fronteiras e Fundamentos Conceptuais das Relações Públicas (pp. 65-87). Covilhã: Labcom.

Santo, P. E. (2010). Introdução à Metodologia das Ciências Sociais: Génese, Fundamentos e Problemas. Lisboa: Edições Sílabo.

Schönhagen, P. \& Meißner, M. (2016). The co-evolution of public relations and journalism: A first contribution to its systematic review. Public Relations Review, 42(5): 748-758.

Sebastião, S. (2009). Comunicação Estratégica: As Relações Públicas. Lisboa: Instituto Superior de Ciências Sociais e Políticas. 
Semetko, H. \& Valkenburg, P. (2000). Framing European Politics: A Content Analysis of Press and Television News. Journal of Communication, 50(2): 93-109.

Tench, R. \& Yeomans, L. (2009). Exploring Public Relations. $2^{\text {nd }}$ Edition. London: Financial Times/Prentice Hall.

Theaker, A. (2004). The Public Relations Handbook. London: Routledge.

Vale, R. d. \& Moreira, I. (2016). Estudo da Sociedade Portuguesa - Confiança no governo, instituições, poupança, e perceção moral e ética. Observatório da Sociedade Portuguesa Católica-Lisbon.

Vicente, I. (2016). Quantos são os lesados do GES, o que vão receber, quem vai pagar e do que vão abdicar. Obtido em Expresso Economia a 31 de agosto de 2017 de: http://expresso.sapo.pt/ec onomia/2016-12-20-Quantos-sao-os-lesados-do-GES-o-que-vao-receber-quem-vai-pagar-edo-que-vao-abdicar

Visão. (2014). Bancocracia: A verdadeira história da crise bancária portuguesa. Obtido em Visão a 10 de fevereiro de 2017: http://visao.sapo.pt/actualidade/portugal/bancocracia-a-verdadeirahistoria-da-crise-bancaria-portuguesa $=\mathbf{f} 749889$ 


\section{Apêndice}

Apêndice 1. Atores e Instituições presentes nas notícias das plataformas digitais dos jornais: Correio da Manhã, Jornal de Notícias, Publico (BES)

\begin{tabular}{|c|c|}
\hline Atores/ Instituições Presentes & Número de Menções \\
\hline Novo Banco & 49 \\
\hline AIEPC & 29 \\
\hline Lesados em nome individual & 15 \\
\hline Banco de Portugal (BdP) & 14 \\
\hline Forças Policiais & 14 \\
\hline CDS-PP & 11 \\
\hline Possíveis Compradores BES (Anbang, Fosun, Apollo) & 10 \\
\hline Passos Coelho & 10 \\
\hline Paulo Portas & 5 \\
\hline Representantes Políticos Europeus (Ângela Merkel, François H & \\
\hline Jean Claude Junker, Mariano Rajoy) & 4 \\
\hline Administração Novo Banco (Stock da Cunha, João Freixa) & 4 \\
\hline Outras Instituições Bancárias (BPN, BEST, Millenium BCP) & 3 \\
\hline Carlos Costa (governador BdP) & 3 \\
\hline CMVM & 3 \\
\hline Ministério das Finanças & 3 \\
\hline Representantes AIEPC (Ricardo Ângelo, Nuno Lopes Pereira) & 3 \\
\hline Presidente da República & 3 \\
\hline PSD & 3 \\
\hline António Costa & 2 \\
\hline Associação de Defesa dos Clientes Bancários & 2 \\
\hline Administração BES (Ricardo Salgado, Jorge Martins) & 2 \\
\hline Associação de Investidores e Analistas Técnicos & 1 \\
\hline Banco Central Europeu & 1 \\
\hline Bloco de Esquerda & 1 \\
\hline PCP & 1 \\
\hline Mário Draghi & 1 \\
\hline PS & 1 \\
\hline Total & 198 \\
\hline
\end{tabular}

Elaboração própria 